\title{
Regional variation and age-related changes of lysosomal enzymes in the human retinal pigment epithelium
}

\author{
Mike Boulton, Patrick Moriarty, John Jarvis-Evans, Borys Marcyniuk
}

\begin{abstract}
In this study the activities of two lysosomal enzymes in retinal pigment epithelial (RPE) cells isolated from three regions of the human fundus were examined: the macula, the nasal midzone, and the periphery. The results obtained showed that the activities of acid phosphatase and cathepsin D were significantly higher in the RPE cells derived from the macular region when compared with those in the periphery. The values for the midzone appeared to be intermediate between the other two regions. Furthermore, the overall activity of both enzymes increased as a function of age. (Br F Ophthalmol 1994; 78: 125-129)
\end{abstract}

Lysosomes are cytoplasmic organelles, each delimited by a single lipoprotein membrane. Typically, they contain a vast array of acid hydrolases capable of degrading all large cellular molecules - nucleic acids, proteins, polysaccharides, and lipids - to low molecular weight products. Lysosomal enzymes are particularly important in the retinal pigment epithelium $(\mathrm{RPE})$ as they are responsible for the degradation of ingested photoreceptor outer segment material. ${ }^{12}$ In addition, RPE lysosomal enzymes degrade inträcellular components sequestered during autophagy, ${ }^{3}$ are a component part of lipofuscin granules, ${ }^{4}$ and may be involved in the degradation or remodelling of melanin granules. ${ }^{5}$ The characteristic spectrum of enzyme activities of RPE lysosomes is thought to reflect degradative functions specific for this tissue. ${ }^{6}$

Regional variation in RPE structure and physiology is now well documented ${ }^{7-16}$ and probably reflects the functional demands from the overlying neural retina, in particular the phagocytic load. Evidence from animal studies suggests that phagocytic load may be reflected in the lysosomal enzyme activities seen in varying regions of the RPE, and that this variation may be species specific. Higher levels of cathepsin D are observed in the area centralis of bovine eyes when compared with cells from the equatorial region. ${ }^{12}$ In contrast, in the dog eye, the regional distribution of lysosomal enzyme activity varies between different enzymes. ${ }^{13}$ Cathepsin $D$ was highest in the central retina while the levels of acid phosphatase, $B$-glucuronidase and $N$-acetyl- $B$-glucosaminidase were highest in the peripheral retina.

This study aimed to determine if human RPE demonstrated a regional variation in lysosomal enzyme activity and if such activity reflected agerelated changes in the retina.

\section{Materials and methods \\ RPE ISOLATION}

Human eyes from 16 individual donors ranging from 17 to 90 years of age were obtained from the Manchester Eye Bank immediately following removal of the corneoscleral rim for grafting. All eyes were obtained within 12 hours post mortem. The remaining anterior portion of the eyes was removed by a circumferential incision immediately posterior to the ora serrata. The vitreous and retina were removed and the eye cup divided into three regions; posterior pole, nasal midzone, and periphery. For the two segments from the nasal midzone and periphery, the cut edges were sealed with Vaseline and the exposed RPE was washed twice with Dulbecco's phosphate buffered saline without $\mathrm{Ca}^{2+}$ and $\mathrm{Mg}^{2+}$ (PBSA) before enzyme treatment. For the posterior pole segment, the macular region was contained within a stainless steel cylinder $(8 \mathrm{~mm}$ internal diameter) sealed in place with Vaseline. ${ }^{17}$ The RPE contained within the cylinder was washed twice with PBSA before enzyme treatment.

The RPE cells were exposed to $0 \cdot 25 \%$ trypsin in PBSA supplemented with $200 \mu \mathrm{g} / \mathrm{ml}$ EDTA for 90 minutes at $37^{\circ} \mathrm{C}$ and detached by gentle aspiration. The resultant cell suspensions were collected and centrifuged at $100 \mathrm{~g}$ for 7 minutes at $10^{\circ} \mathrm{C}$. The supernatant fluid was removed, and the pellet of cells resuspended in $1 \mathrm{ml}$ PBSA. The number of cells in these suspensions was determined using a haemocytometer. The cell suspensions were then adjusted to $8 \times 10^{4}$ cells $/ \mathrm{ml}$ and 25 $\mu l$ aliquots $\left(2 \times 10^{3}\right.$ cells $)$ were placed in each well of a 96 well microtitre plate for enzyme assays. The enzyme activities were corrected for the number of cells isolated and therefore expressed per number of cells. The washings and supernatant fluids were also kept for analysis.

\section{ENZYME ASSAYS}

The activities of acid phosphatase and cathepsin $\mathrm{D}$ were assayed as previously described. ${ }^{18}$ In brief, the $25 \mu \mathrm{l}$ aliquots of cell suspensions introduced into each well of a microtitre plate were lysed by the addition of $0 \cdot 2 \%$ Triton X-100 in distilled water, after which buffer and substrate solutions were added. Four wells were used for each sample and assays were carried out on a minimum of two separate occasions. Acid phosphatase measurements were carried out on all donor eyes obtained while cathepsin $D$ assays were only undertaken where sufficient cells were available.

Acid phosphatase activities were assayed in

Departments of
Ophthalmology and Cell
and Structural Biology,
University of
Manchester, Manchester
M Boulton
P Moriarty
J Jarvis-Evans
Manchester Royal Eye
Hospital, Manchester
B Marcyniuk
Correspondence to:
Dr Mike Boulton, University
Department of
Ophthalmology, Manchester
Royal Eye Hospital, Oxford
Road, Manchester M13 9PQ.
Accepted for publication
23 September 1993


$0 \cdot 1 \mathrm{M}$ acetate buffer ( $\mathrm{pH} \mathrm{4.5)}$. A $5 \mathrm{mM}$ solution of $p$-nitrophenyl phosphate was used as substrate. The reaction was stopped after 30 minutes by the addition of $0.26 \mathrm{M} \mathrm{NaOH}$. The absorption of light by $p$-nitrophenyl released in the enzyme reaction was measured at $405 \mathrm{~nm}$ using a Titertek ELISA reader (Flow, UK) and converted to pmoles of reaction product using a calibration curve for $p$-nitrophenol.

Cathepsin D activity was assayed in Triton treated cell suspensions incubated in $0.25 \mathrm{M}$ formate buffer ( $\mathrm{pH} 3.3$ ) using $2 \%$ bovine haemoglobin (Sigma) as substrate for 60 minutes at $37^{\circ} \mathrm{C}$. ${ }^{19}$ The reaction was terminated by addition of $3 \%$ trichloroacetic acid after which the microtitre plate was centrifuged at $250 \mathrm{~g}$ for 10 minutes at $10^{\circ} \mathrm{C}$. Aliquots of the supernatant were transferred to a second plate and assayed for soluble proteolytic products by a modification of the Lowry method. ${ }^{19}$ The resulting absorptions at $690 \mathrm{~nm}$ were then converted to tyrosine equivalents using a calibration curve.

Appropriate controls ${ }^{18}$ were incorporated in every experiment and included reaction mixture without cells and reaction mixture plus cells in which the reaction was stopped at time zero. The activity assayed for all enzymes was linear with time and proportional to the number of cells assayed. The enzyme activity was expressed as pmoles of $p$-nitrophenol or ng of tyrosine equivalents/minute/number of cells.

\section{STATISTICS}

The results for each enzyme were analysed for the three regions by paired Student's $t$ test with Bonferroni correction to account for generation of significant differences by multiple comparisons. $p$ Values $<0.05$ were considered significant.

Figure 1 Acid phosphatase activity assayed in fresh retinal pigment epithelial cells isolated from donors of different ages. The values represent four assays per sample from each region. Vertical bars represent SEM. $P N P=$ p-nitrophenol.

\section{Results}

Acid phosphatase and cathepsin D activity were detected in RPE cells from all three regions of the fundus. The activities demonstrated a consistent regional variation within individual eyes but

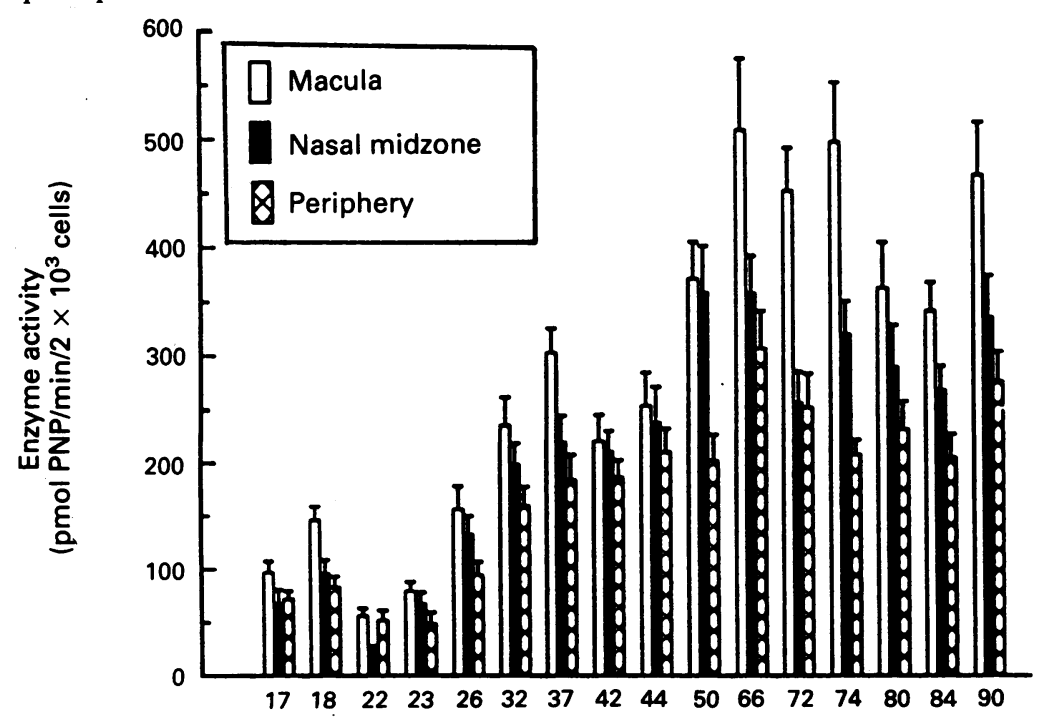

Age (years) overall enzyme levels increased with increasing donor age (Figs 1 and 2).

For both acid phosphatase and cathepsin $\mathrm{D}$ the enzyme activity was significantly higher in the macular region than in either the nasal midzone or the periphery $(p<0.002)$. Enzyme activities in the nasal midzone region were intermediate between the macula and the periphery. The statistical significance of the data is given in Table 1.

The overall activity of both enzymes, in all regions, increased as a function of donor age (Fig 3). Acid phosphatase activity progressively increased in all regions as donor age increased from 30 to 65 years of age. Enzyme levels remained relatively constant in the less than 30 year and more than 60 year age groups. In all retinal regions the enzyme activities were significantly higher in the more than 60 year age group when compared with the less than 30 year age group $(p<0.005)$. In addition, for the macular and peripheral regions, the enzyme activities of the 30 to 60 year age group were significantly higher than those in the less than 30 age group $(p<0.001)$ and significantly lower than those in the more than 60 year age group $(p<0.05)$. While regional variation was observed in all eyes the difference in acid phosphatase activity between macula and periphery was most pronounced in the $\geqslant 50$ year age group (Fig 1 ).

The increase in cathepsin D levels as a function of age was less pronounced than that observed for acid phosphatase (Fig 3). Enzyme activity in the periphery showed a similar trend to that with acid phosphatase in that the enzyme levels increased as donor age increased from 30 to 65 years of age and remained relatively constant thereafter. In all retinal regions the enzyme activities were significantly higher in the more than 60 year age group when compared with the less than 30 year age group $(p<0.05)$. Only for the peripheral region were the enzyme activities of the 30 to 60 year age group significantly higher than those in the less than 30 age group $(\mathrm{p}<0.04)$ and significantly lower than those in the more than 60 year age group $(\mathrm{p}<0.03)$.

Washings from RPE cells before detachment did not have detectable enzyme activity. Supernatant fluids from pelleting the isolated cells exhibited low levels of activity for both enzymes ( $\leqslant 14 \%$ of total enzyme activity). Where measurable these activities followed the same regional distribution found for the corresponding cells.

\section{Discussion}

In this study we have shown that the activities of two lysosomal hydrolases in the human RPE vary with retinal location and increase in all regions of the retina as a function of age. Topographical variation in lysosomal enzyme activities has been reported for both primates (in which the RPE is pigmented throughout the retina and which have a defined macula) and for species such as the cow and $\operatorname{dog}$ (in which the RPE in the central superior area of the fundus is non-pigmented and which have a primitive 'macula' called the area centralis). The only previous study on human tissue, using RPE/choroid preparations from different regions of two human eyes, demon- 


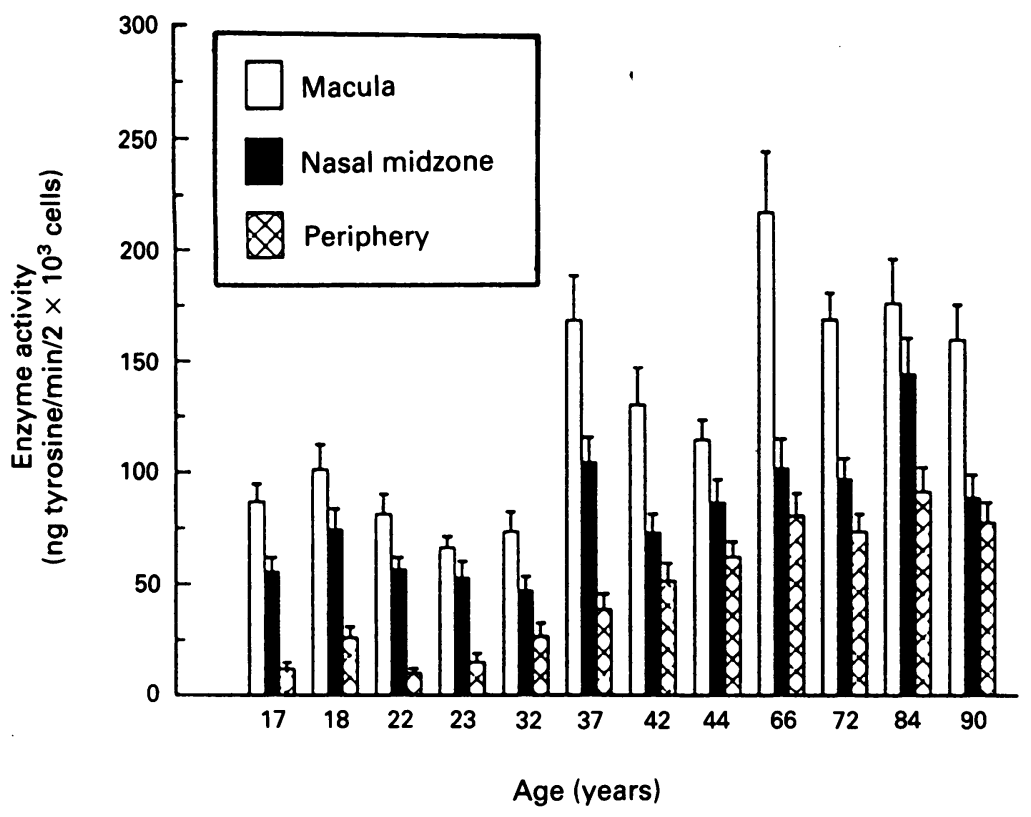

Figure 2 Cathepsin D activity assayed in fresh retinal pigment epithelial cells isolated from donors of different ages. The values represent four assays per sample from each region. Vertical bars represent SEM.

Figure 3 Overall activities of acid phosphatase and cathepsin $D$ as a function of age. Separate graphs are shown for each retinal region. $P N P=$ p-nitrophenol.
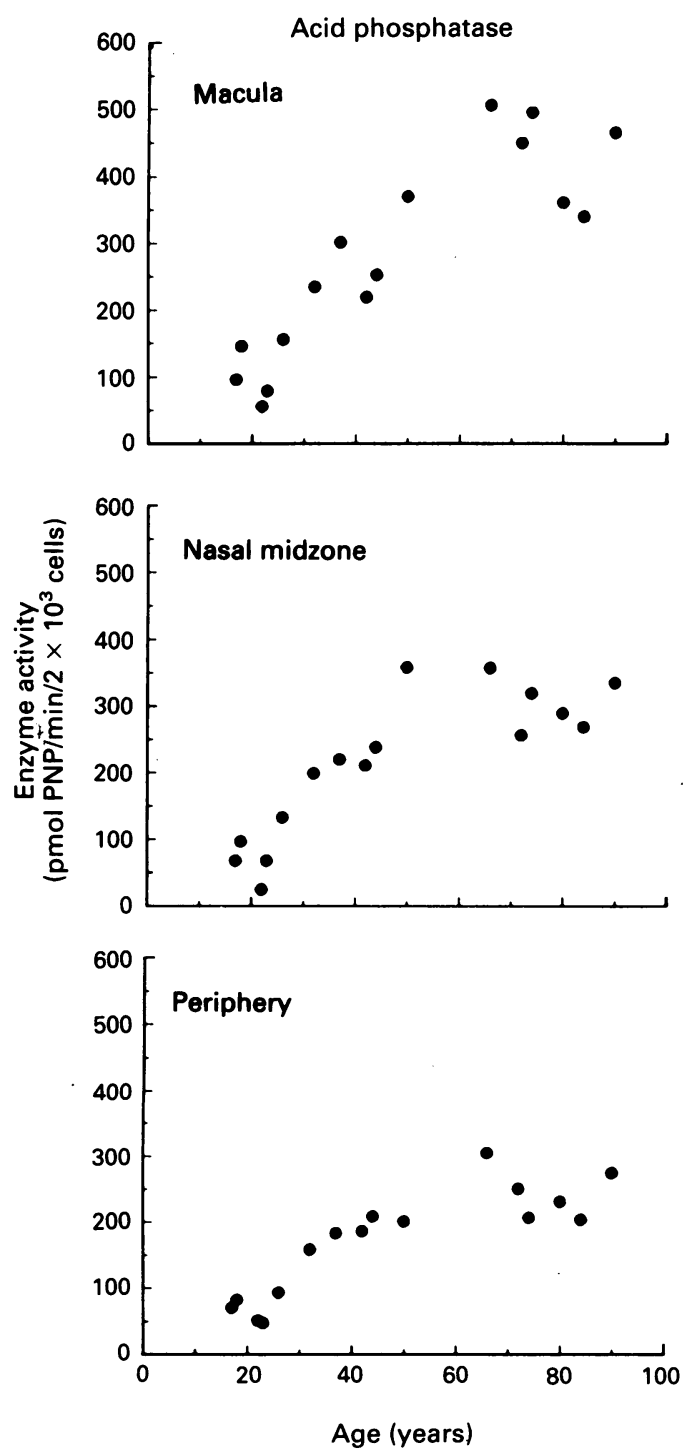

strated that the enzyme activities for cathepsin D, arylsulphatase and acid phosphatase were higher in the macular region than in the remaining areas of the retina. ${ }^{10}$ Our more comprehensive study using isolated RPE cells confirms that the RPE layer makes a significant contribution to the elevated lysosomal enzyme activities in the posterior pole. A similar observation was made in the bovine eye by Burke and Twining who found higher levels of cathepsin D activity in the posterior area centralis when compared with RPE cells from the equatorial region. ${ }^{12}$ In contrast, in the dog eye, Cabral et al reported that the regional distribution of lysosomal enzyme activity can vary between different enzymes. ${ }^{13}$ Cathepsin D activity was highest in the central retina while the levels of acid phosphatase, $B$-glucuronidase, and $N$-acetyl-B-glucosaminidase were highest in the peripheral retina.

Such regional variations in the biochemical activity of the RPE are not restricted to lysosomal hydrolases since topographical variations reported include those for cytochrome oxidase, sodium/potassium ATPase pump density, and cyclic nucleotide content. ${ }^{14} 1520$

Although the macular region exhibited the highest overall levels of enzyme activity, it was not possible to determine whether this activity was evenly distributed across the $8 \mathrm{~mm}$ diameter
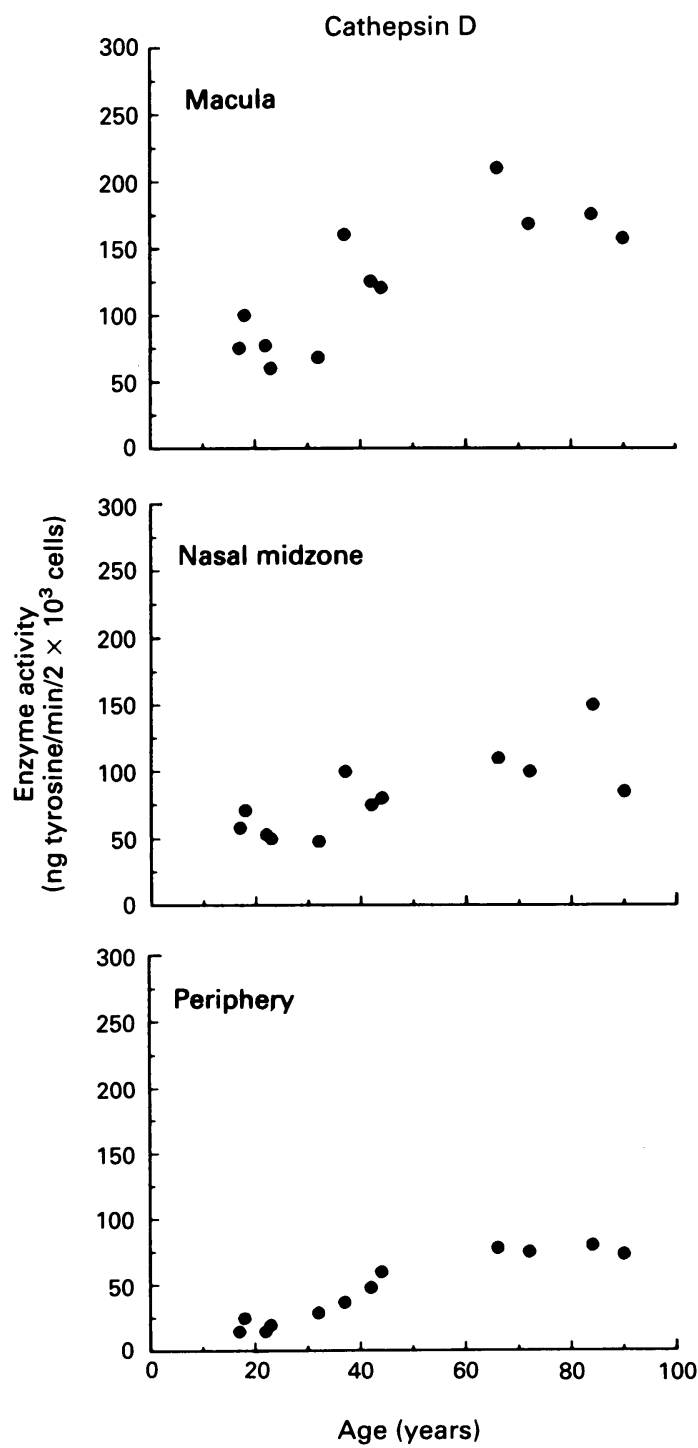
area isolated or whether high levels of activity were localised to a discrete zone within this area (for example, the fovea).

Two hypotheses could account for the differences observed in the activity of lysosomal enzymes in RPE cells from different regions of the retina. Firstly, different populations of RPE cells could differ in their steady state equilibrium as a result of variations in their genetic expression, or, secondly, different populations of RPE cells with the same steady state equilibrium could be subject to different environmental modulatory factors resulting in a new steady state. Given the marked variation in retinal structure and function the latter hypothesis is most attractive and is supported by the age-related increase in overall enzyme activity. Since the major function of the RPE lysosomes is the degradation of ingested photoreceptor outer segments it is reasonable to consider that regional differences may reflect the amount of material phagocytosed (that is, photoreceptor type, photoreceptor density, or the rate of photoreceptor ingestion). Additional support for the second hypothesis comes from in vitro studies in which the regional variation seen in fresh RPE is not apparent in cultured RPE, , 12 suggesting that lysosomal enzyme activities are dependent on environmental modulatory factors which are not present in culture (for example, phagocytic challenge).

It is clear from these studies that there is a trend towards higher activities of lysosomal enzymes in the RPE with increasing donor age. There was a significant age-related correlation for acid phosphatase activity in the macular and peripheral retina, and for cathepsin $\mathrm{D}$ activity in the peripheral retina. It is likely that a positive correlation between age and enzyme activity would have been observed in the other retinal regions if a greater number of donor eyes had been examined. The observation of an agerelated increase in lysosomal enzyme activities is supported by similar observations in non-ocular tissues. ${ }^{21-24}$

The observed age-related increase in RPE lysosomal enzyme content may be explained in a number of ways. Firstly, this increase may reflect increased phagocytic load on the RPE with age. However, reports on the photoreceptor/RPE ratio in humans are inconsistent. Dorey et al reported that the mean ratio of photoreceptors to RPE cells was higher in the macula than in either the paramacular or equatorial area, and that this ratio increased with increasing donor age..$^{25}$ In contrast, a more recent study by Gao and Hollyfield failed to reveal a difference in photoreceptor/RPE ratios between the fovea and equator or an age-related increase in photoreceptor/RPE ratios. ${ }^{26} \mathrm{~A}$ second explanation for age-related increases in enzyme activity may reflect the association of lysosomes with pigment granules (that is, melanosomes and lipofuscin). Melanolysosomes are known to accumulate progressively within the RPE throughout life. ${ }^{5}$ This association of lysosomes with melanosomes may necessitate an increase in lysosome numbers in order to maintain the normal degradative cycle following outer segment ingestion by RPE cells (no attempt was made to determine lysosome numbers per RPE cell in this study). However, this interpretation is open to debate. Cabral et al were unable to find a correlation between melanosome content and lysosomal enzyme activity in RPE cells isolated from dog eyes ${ }^{13}$ and studies on human RPE cells, while documenting an agerelated increase in pigment complexes, have failed to differentiate between melanolipofuscin granules and melanolysosomes.

The accumulation of lipofuscin within the $\mathrm{RPE}$ is reported to be bimodal ${ }^{27}$; considerable accumulation of lipofuscin occurs within the first two decades of life, plateaus during the third decade, and starts to increase again from fifth decade onwards. Topographically, a maximal accumulation of lipofuscin granules occurs in the posterior pole albeit with a decrease at the fovea. ${ }^{28}$ This distribution of lipofuscin as a function of retinal location remains constant throughout life. ${ }^{828}$ Furthermore, it is now well established that the material constituting the lipofuscin pigment is located within the lysosomal vacuome. ${ }^{16}$ Thus, both the regional distribution and the age-related increase in lysosomal enzyme activity observed in this study could reflect the association of lysosomes with lipofuscin granules. Furthermore, the progressive increase in lysosomal enzyme activity between the third and sixth decade suggests an inverse relationship between lysosomal enzyme activity and the bimodal accumulation of lipofuscin. While this infers that the increase in lysosomal enzymes with age does not reflect association of lysosomes with lipofuscin granules it could, however, reflect an increased turnover of lysosomal hydrolases due to the association of lysosomes with newly forming lipofuscin granules in the younger and older age groups.

It should be emphasised that this study examines lysosomal enzyme activity in RPE cells and may not reflect total enzyme protein. This may be particularly pertinent to the age-related changes for which there is a precedence for nonenzymatic, post translational, amino acid modification of proteins resulting in changes in enzyme activity. ${ }^{29}{ }^{30}$ Furthermore, the results presented do not exclude the possibility that enzyme activity is regulated by as yet unidentified factors in the RPE.

The regional variations in enzymic content of RPE lysosomes could contribute to the regional distribution of some of the changes in the structure of the outer retina which are associated with both age and retinal disease. Further studies are required to provide an insight into the mechanisms for this regional specialisation as well as its physiological consequences.

This work was supported by the Macula Foundation, Inc, USA; North West Regional Health Authority; and Manchester Royal Eye Hospital Endowments.

1 Ishikawa T, Yamada E. The degradation of the photoreceptor outer segment within the retinal pigment epithelial cell of rat retina. F Electron Microsc 1970; 19: 85-99.

2 Young RW, Bok D. Participation of the retinal pigment epithelium in the rod outer segment renewal process. $\mathcal{F}$ Cell Biol 1969; 42: 392-403.

3 Reme CE. Autophagy in visual cells and pigment epithelium. Invest Ophthalmol Vis Sci 1977; 16: 807-14.

4 Brunk U, Ericsson JL. Electron microscopical studies on rat brain neurons. Localisation of acid phosphatase and mode of brain neurons. Localisation of acid phosphatase and mode of
formation of lipofuscin bodies. F Ultrastruct Res 1972; 38: formation.

5 Feeney $L$. Lipofuscin and melanin of human retinal pigment epithelium: fluorescence, enzyme cytochemical and ultrastructural studies. Invest Ophthalmol Vis Sci 1978; 17: $583-600$. 
6 Zimmerman W, Godchaux W, Belkin M. The relative proportions of lysosomal enzyme activities on bovine retinal pigment epithelium. Exp Eye Res 1983; 36: 151-8.

7 Streeten BW. Development of the human retinal pigment epithelium and the posterior segment. Arch Ophthalmol 1969; 81: 383-94

8 Wing GL, Blanchard GC, Weiter JJ. The topography and age relationship of lipofuscin concentration in the retinal pigment epithelium. Invest Ophthalmol Vis Sci 1978; 17: 601-7.

9 Hayasaka S. Distribution of lysosomal enzymes in the bovine eye. Fpn f Ophthalmol 1974; 18: 223-39.

10 Hayasaka S, Shiono T, Hara S, Mizuno K. Regional distribution of lysosomal enzymes in the retina and choroid human eyes. Graefes Arch Klin Ophthalmol 1981; 216: 269-74.

11 Weiter JJ, Delori FC, Wing GL, Fitch KA. Retinal pigment epithelial lipofuscin and melanin and choroidal melanin in epithelial lipofuscin and melanin and choroidal melanin in

12 Burke JM, Twining S. Regional comparisons of cathepsin D in bovine retinal epithelium. Invest Ophthalmol Vis Sci 1988; 29: 1789-93.

13 Cabral L, Unger W, Boulton M, Lightfoot R, McKechnie N, Grierson I, et al. Regional distribution of lysosomal enzymes in the canine retinal pigment epithelium. Invest Ophthalmol Vis Sci 1990; 31: 670-6.

14 Burke JM, Murray TG. Regional comparisons of cytochrome oxidase activity in retina and RPE. Invest Ophthalmol Vis $S c i$ 1990; 31 (suppl): 492.

15 McKay BS, Burke JM. RPE cells of the posterior pole have fewer $\mathrm{Na} / \mathrm{K}$ ATPase pumps than peripheral cells. Invest Ophthalmol Vis Sci 1990; 31 (suppl): 492.

16 Boulton ME. Ageing of the retinal pigment epithelium. In: Osborne NN, Chader GJ, eds. Progress in retinal research. Vol 11. Oxford: Pergamon Press, 1991: 125-51.

17 Boulton ME, Marshall J, Mellerio J. Human retinal pigment epithelial cells in tissue culture: a means of studying inherited retinal disease. In: Cotlier E, Maumanee IH, Berman ER, eds. Genetic eye diseases: retinitis pigmentosa and other inherited eye disorders. Vol 18. New York: Alan R Liss 1982: 101-18.

18 Cabral L, Unger W, Boulton M, Marshall J. A microsystem to assay lysosomal enzyme activities in cultured retinal pigment epithelial cells. Curr Eye Res 1988; 7: 1097-104.

19 Barret AJ, Heath MF. Lysosomal enzymes. In: Dingle JT, ed. Lysosomes: a laboratory handbook. Amsterdam: Elsevier, 1977: 20-145.

20 Newsome DA, Fletcher RT, Chader GJ. Cyclic nucleotides vary by area in the retina and the pigment epithelium of the human and monkey. Invest Ophthalmol Vis Sci 1980; 19: 864-71.

21 Nakamura $Y$, Takeda $M$, Suzuki $H$, Morita H, Tada K, Haraguchi S, et al. Age-dependent change in activities of lysosomal enzymes in rat brain. Mech Ageing Dev 1989; 50 : 215-25.

22 Sanderson $\mathrm{CL}$; Leslie $\mathrm{S}$. Cathepsin B, D and $\mathrm{H}$ in muscles of chicks of fast and slowing growing strains: effect of age and diet. Comp Biochem Physiol [A] 1989; 92: 305-11.

23 Alberghina M, Guiffrida-Stella AM. Age-related changes of ribonuclease activities in various regions of the rat central nervous system. I Neurochem 1988; 51:21-4.

24 Ferland G, Perea A, Audet M, Tuchweber B. Characterization of liver lysosomal enzyme activity in hepatocytes, Kupffer and endothelial cells during aging: effect of dietary restriction. Mech Ageing Dev 1990; 56: 143-54.

25 Dorey CK, Wu G, Ebenstein D, Garsd A, Weiter JJ. Cell loss in the ageing retina: relationship to lipofuscin accumulation in the ageing retina: relationship to lipofuscin accumulation and macular

26 Gao H, Hollyfield JG. Aging of the human retina. Differential loss of neurons and retinal pigment epithelial cells. Invest Ophthalmol Vis Sci 1992; 33: 1-17.

27 Weale RA. Do years or quanta age the retina? Photochem Photobiol 1989; 50: 429-38.

28 Marshall J. The ageing retina: physiology or pathology. Eye 1987; 1: 282-95.

$29 \mathrm{McHerrow} \mathrm{JH}$. Non enzymatic, post-translational, amino acid modification in ageing, a brief review. Mech Ageing Dev 1979; 10: 371-7.

30 Sharma HK, Prasanna HR, Rothstein M. Altered phosphoglycerate kinase in aging rats. $\mathcal{F}$ Biol Chem 1980; 255: 5043-50. 